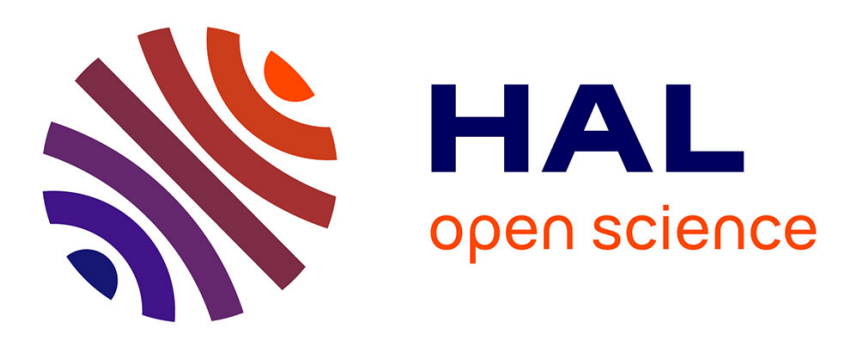

\title{
Mobile advertising: the effect of tablet tilt angle on user's purchase intentions
}

Caroline Ardelet

\section{To cite this version:}

Caroline Ardelet. Mobile advertising: the effect of tablet tilt angle on user's purchase intentions. Journal of Marketing Communications, In press. hal-01841432

\section{HAL Id: hal-01841432 \\ https://hal.parisnanterre.fr/hal-01841432}

Submitted on 27 Aug 2018

HAL is a multi-disciplinary open access archive for the deposit and dissemination of scientific research documents, whether they are published or not. The documents may come from teaching and research institutions in France or abroad, or from public or private research centers.
L'archive ouverte pluridisciplinaire HAL, est destinée au dépôt et à la diffusion de documents scientifiques de niveau recherche, publiés ou non, émanant des établissements d'enseignement et de recherche français ou étrangers, des laboratoires publics ou privés. 


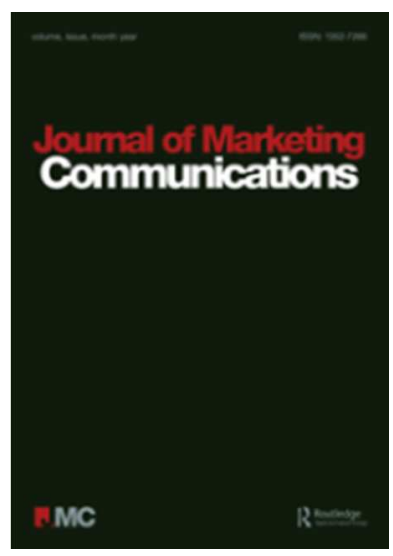

Mobile advertising: the effect of tablet tilt angle on user's purchase intentions

\begin{tabular}{|r|l|}
\hline Journal: & Journal of Marketing Communications \\
\hline Manuscript ID & RJMC-2017-0090.R3 \\
\hline Manuscript Type: & Original Papers \\
\hline Keywords: & mobile, internet, body, position, perspective, tilt angle \\
\hline \multicolumn{2}{|}{} \\
\hline
\end{tabular}

SCHOLARONE ${ }^{m}$

Manuscripts 


\title{
Mobile advertising: the effect of tablet tilt angle on users' purchase intentions \\ Caroline Ardelet
}

\begin{abstract}
With the advent of mobile screens, online advertisements are viewed on screens held in various positions, from horizontal (such as when the tablet is rested on a table or on the knees) to vertical (when placed on an easel, for example), allowing the viewer to see the advertisement in different body postures. Based on the theory of embodied cognition (Barsalou, 2008), we present two experimental studies in which we show (1) that mobile device tilt angle impacts purchase intention of advertised products, (2) that purchase intention is increased when device tilt angle allows viewers to stand in a body posture that is consistent with the image perspective, and (3) that mental simulation process mediates this effect. The results contribute to a better understanding of the conditions of advertising effectiveness on mobile devices.
\end{abstract}

Key words: mobile; internet; body; position; perspective; tilt angle; gyro marketing 


\section{Mobile advertising: the effect of tablet tilt angle on users' purchase intentions}

E-commerce growth is primarily being driven by consumers using their mobile devices, phones and tablets, to acquire goods and services (statista, 2018). Retail e-commerce sales reached $\$ 2.3$ trillion in 2017 , a $23.2 \%$ increase over the previous year. The mobile share of this stood at $58.9 \%$, or $\$ 1.4$ trillion. In 2021 , mobile e-commerce could rake in some $\$ 3.5$ trillion and then make up almost three quarters $(72.9 \%)$ of e-commerce sales (statista, 2018). Laptop and PC e-commerce drops off, although e-commerce on smartphones and tablets increases dramatically.

Many industries that rely on e-commerce are challenged by the rise of mobile interfaces because they fundamentally change the experience of the online advertisement. The body posture consumers adopt as they stare at their mobile screen (smartphone and tablet) is very different from laptop and desktop users' posture. While using mobile devices, consumers may hold the screen flat (near-horizontal device position) or hold the screen straight (near-vertical device position). Therefore, depending on how the mobile device is tilted, a mobile ad can be seen by viewers bending their head forward and dropping their chin on to their chest (downward head position) or by viewers keeping their head straight and looking forward to the screen (frontward head position).

Surprisingly, the impact of device tilt angle position and viewers' body posture on mobile advertising efficacy has received little attention in literature. Research shows that purchase intention towards advertised product is determined by mental simulation processes provoked by the advertisement (e.g. Elder and Krishna, 2012). Product mental simulation is a form of automatic mental imagery process that helps individuals to mentally imagine product interaction. Various features of advertisements have been 
shown to impact mental simulation and purchase intention: product orientation within the picture (Förster, 2004; Elder and Krishna, 2012), camera viewing angles (RoyoVela and Black, 2018; van Rompay, de Vries, and Bontekoe, 2012) or wording of messages on the ad (Escalas 2004, 2007; Jeong and Jang 2016). But literature has not yet examined the potential impact of the media device position on mental simulation and purchase intention towards the advertised product.

Yet, embodied cognition literature highlights that body postures have a strong impact on information processing and decision making (Barsalou, 2008). Several studies demonstrate that approach behaviors towards objects vary depending on individuals' actual body postures (Förster, 2004). For example, Van Kerckhove, Geuens, and Vermeir (2015) show that consumers prefer and choose different products when they look down versus up. Indeed, mental simulation with the product is facilitated, and purchase intentions are increased, when viewers' body postures are aligned with product orientation within the ad (Elder and Krishna, 2012).

Depending on how the mobile device is held (near-horizontal or near-vertical tilt angle position), the product advertised in the mobile ad can be aligned (or unaligned) with actual viewers' body posture. In instance, when the product is photographed with a downward view to the object (so called birds' eyes perspective), viewers holding their mobile device in a near-horizontal position (tilting their head forward and dropping their chin on to their chest in a downward head position) should stand in a body posture that is aligned with product orientation within the ad. To the contrary, when the product is photographed with a frontward view to the object (so called frontal perspective), viewers' body posture should be aligned with the advertised product orientation when they hold their device straight in a near-vertical position (keeping their head straight and looking forward to the screen in a frontward head position). 
In this paper, we focus on the impact of mobile device tilt angle on mental simulation processes and purchase intention of advertised products. We present two experimental lab studies where we manipulate mobile device position (near-horizontal or nearvertical device tilt angle position) and product image perspective in the ad (vertical view to the object, so-called birds' eyes perspective or frontal view to the object, so-called frontal perspective). We study whether vertical (vs frontal) viewers' head position required by mobile device position (near-horizontal or near-vertical tilt angle position) impacts mental simulation and purchase intention for advertised products on mobile devices. In doing so, we extend the literature on mental simulation with advertised products (e.g. Royo-Véla and Black, 2018; Choi and Taylor, 2014; Elder and Krishna, 2012; Förster, 2004) by underlining the role of the device tilt angle, mental simulation and purchase intention.

In the first section, we define the conceptual framework that allows us to establish research hypotheses. Next, we present the two experimental studies that we conducted on users of digital tablets. In the first study, we show that purchase intention towards an advertised product varies when the internet user is holding the tablet flat (in a so-called "near horizontal" position) or upright (a so-called "near vertical" position). In the second study, we show that tablet tilt angle impacts purchase intention towards advertised product because it creates a consistency (or inconsistency) with the viewer's body posture, that promotes (or reduces) mental simulation with the advertised product. Finally, the article reaches a conclusion on the contributions and limitations of the research and suggests several avenues for future research.

\section{THEORETICAL FRAMEWORK}

\section{Mobile device tilt angle and viewers' body posture}


Recent research highlights that perceptions of online advertised products and purchase intentions are impacted by the way viewers interact with them (Brasel and Gips, 2014; Shen et al., 2016).

One distinctive feature of tablets and smartphones is that they are held in the hand of the viewer. Therefore, unlike a desktop computer which is always positioned vertically (usually against a wall), mobile devices are held in various positions, such as horizontally (when rested on the knees, for example) or vertically (when standing straight).

Therefore, mobile advertisements can be viewed with different head positions (see figure 1 for an example). Indeed, ergonomics research has shown that individuals adapt their entire body posture to the tilt angle of the mobile device. Even though the eye can move in its socket, people tend to adjust their head and neck posture to the position in which the mobile device is held (Young et al., 2012; Chian-Son and Wachara, 2016). When the mobile device is tilted forward (near-horizontal device position), the chin is dropped on to the chest, the head is tilted forward (Hansraj, 2014) and the mobile advertisement is viewed with the head in a downward position (Vasavada et al., 2015). On the other hand, when the device is held straight in front (near-vertical device position), the head remains straight in a frontward position.

Embodied cognition literature highlights that body postures have a strong impact on information processing and decision making (Barsalou, 2008). Several studies demonstrate that approach behaviors towards objects vary depending on individuals' actual body postures (Förster, 2004). For example, Van Kerckhove, Geuens, and Vermeir (2015) show that consumers prefer and choose different products when they look down versus up. 
Various theories are explored to explain how body postures can influence advertising perception and behavioral reactions (for a review see Förster, 2004). Many empirical studies show that human individuals tend to get ready to implement the appropriate body movement when they are exposed to a visual image of a product (Schlosser, 2003). Therefore, consistency between product orientation and viewers' body postures results in increased approach behaviors. This effect is called the principle of perceptualmotor compatibility (Förster, 2004). It shows that approach behavior towards advertised products tends to be activated more easily and faster by the viewer when his actual body posture is in line with the gesture that he would have to perform to grasp the product in is hand. For instance, Elder and Krishna (2012) demonstrate that purchase intention for a product orientated to the left (vs right) within the advertisement is higher when viewers stand with their left (vs right) hands ready for usage, and their right (vs left) hands occupied with a physical task that prevents their usage. As far as mobile advertising is concerned, with viewers' body postures depending on device tilt angle position (frontward when device is held in a near-vertical position and downward when device is held in a near-horizontal position), purchase intention towards advertised products should vary depending on how the viewers' position is in line with the way the product is depicted within the advertisement.

In advertising, there are several ways of depicting an object. In front-views perspective, the camera is positioned in front of the product although in high-angle views, the camera is positioned above the product. Following the perceptual-motor compatibility principle (Förster, 2004), approach behavior towards products on frontal perspective advertisements should be easier to activate when the mobile device is held in a nearvertical position that allow the viewers to keep their heads straight and to look at the picture in front of them. Approach behaviors should thus be higher because the 
frontward position of their head is consistent with the frontward perspective of the picture. Conversely, advertisements showing products from a high-angle perspective should trigger stronger purchase intention if they are seen on a device held horizontally. Indeed, high-angle pictures show the products from the top, and approach behaviors should thus be increased when viewers hold their device flat so as to bend their head downward, because the birds' eye view of the product is consistent with the downward position of the viewers' head.

Building on this literature, we hypothesize:

H1: Purchase intention of advertised product is higher when the mobile device is held in a position that is consistent with the advertised product orientation, in such a way that viewers with a frontward head position watch front-view product advertisement (H1a) and viewers with a downward head position watch high-angle view product advertisements (H1b)

-Figure 1-

\section{Mental simulation towards advertised products in advertisement}

Advertising research shows that purchase intention towards advertised product is determined by mental simulation processes provoked by the product picture on the advertisement (Choi and Taylor, 2014; Elder and Krishna, 2012). Mental simulation, or the reenactment of perceptual experiences, is an automatic form of mental imagery that is initiated by exposure to visual representations of objects. Product mental simulation is an automatic operative process that helps individuals to imagine product interaction. Seeing a visual depiction of a product automatically activates a quick cerebral motor 
response that consists in imagining how to use the product. The link between mental simulation and motor responses has been demonstrated several times with neuroscientific studies (e.g. Chao and Martin, 2000). Several authors (e.g. Choi and Taylor, 2014) establish a causal link between body postures, mental simulation with the product, and purchase intention. Indeed, advertised products cannot be physically tested, manipulated, or touched, and viewers tend to automatically perform a mental simulation of the advertised product to determine whether they like the product and want to buy it (Elder and Krishna, 2012). Many studies have shown that the ease with which a product is mentally visualized does not change attitudes (Schlosser, 2003; Elder and Krishna, 2012; Choi and Taylor, 2014) and has a direct positive effect on the intent to buy the object (Gregory, Cialdini, Carpenter, 1982; Schlosser, 2003; Choi and Taylor, 2014). Indeed, approach behaviors toward products in an advertisement are the consequence of a mental process in which the approach movements are first mentally prepared as part of mental imagery or mental simulation activities (Stanford University's Encyclopedia of Motor Cognition). Mentally imagining a product in an advertisement acts directly on behavior without going through an affective route during which the product would be assessed further (Choi and Taylor, 2014).

According to embodied cognition theory (Barsalou, 2008), body postures affect advertising information processing, and behavioral reactions for advertised products, because they affect how easily viewers can mentally simulate the movement needed to mentally grasp or use the product in the advertisement (Shen, Zhang and Krishna, 2016; Elder and Krishna, 2012). Various features of the ad have been shown to impact the mental simulation process, which in turn impacts purchase intentions : product orientation within the picture (Förster, 2004; Elder and Krishna, 2012), camera viewing angles in the picture (van Rompay, de Vries, and Bontekoe, 2012; Royo-Véla and 
Black, 2018) or wording of messages on the ad (Escalas 2004, 2007; Jeong and Jang, 2016). Empirical studies show that the visual perspective on a product (e.g. vertical pictures taken from a drone or grounded perspective) may result in modified information processing of advertising, such as modified mental simulation processes (Royo-Véla and Black, 2018). In particular, research shows that mental simulation with a product is stronger when there is consistency between the viewers' body posture and the product perspective in the advertisement. Some studies examine the impact of product orientation within the picture (e.g. the handle of a mug is orientated to the left or the right within the picture of the advertisement) (e.g. Elder and Krishna, 2012). They demonstrate that consistency between product orientation (to the left or to the right) and viewer's body posture leads to increased mental simulation and purchase intention. Other studies focus on image perspective and demonstrate that alignment of the viewer's gaze direction with image perspective facilitates mental simulation with advertised product and increases purchase intention (Schlosser, 2003; Jiang et al., 2014). Indeed, mental simulation is facilitated when viewer's body posture is consistent with the mental movement that is needed to mentally grasp the advertised product.

As far as mobile advertising is concerned, building on these previous studies, mental simulation should be easier, and purchase intentions higher, when the device is held in a tilt angle position that allows the viewer to align his body posture with the product image perspective within the advertisement. Indeed, when device position allows the viewers to stand in a body posture that is consistent with the picture perspective, viewers can easily perform a mental interaction with the advertised product and declare higher purchase intention for the advertised product.

When product is displayed in a high-angle perspective (birds' eye view), the camera positioned above the product suggests that the mental movement needed to grasp the 
product is a downward movement. Therefore, the mental simulation with the product should be easier when the device is held flat because it allows the viewers to stand with a downward head posture that is consistent with the image perspective. Indeed, in this tilt angle position, viewers have to bend their head downward, ready to perform a downward mental movement of approach toward the advertised product. Thus, holding the device flat provokes a consistency between image perspective and viewer's body posture when the advertisement is a high-angle (birds' eye) product image perspective. To the contrary, when the product is shot with a front-view perspective, mental movement needed to mentally interact with the product is a frontal movement. Mental simulation with the product is easier, and purchase intention is higher, when the device is held near-vertically because it allows the viewers to keep their head straight, ready to activate a frontal mental approach movement towards the advertised product.

H2: Mental simulation of advertised product is increased when the mobile device is held in a position that is consistent with the advertised product orientation, in such a way that viewers with a frontward head position watch front-view product advertisements (H2a) and viewers with a downward head position watch high-angle view product advertisements (H2b)

H3: Mental simulation of advertised product mediates the impact of the consistency between mobile device position and advertised product orientation on purchase intention towards advertised product 


\section{EXPERIMENTAL STUDIES}

\section{Pilot study}

We conducted two pilot studies in order to determine in what positions internet users usually hold their tablet. The objective is to test the hypotheses on positions that are often used by internet users and thereby maximize the external validity of the results.

To do so, we conducted a study of usage patterns on digital tablets. This study was conducted by e-mail via the software wysuforms. It was sent to 150 undergraduate students in a French management university and resulted in the collection 130 responses from tablet users ( $43 \%$ of men, $57 \%$ of women). Various questions were asked about their tablet usage (preferred tablet brand, tablet use frequency), and especially what type of body posture they adopted while using their tablet. Various body postures were proposed and respondents were asked to evaluate how often they adopted the specific body posture for tablet and laptop usage (never, very rarely, rarely, often, very often, nearly always, always). For example, they were asked how often they sat on couch or armchair when they use their tablet, and how often they sat down in a working position to use their device. The results reveal that $84 \%$ of respondents use always or nearly always their tablet on a couch or an armchair (compared to only $29.4 \%$ for laptops). Only $6 \%$ of the individuals queried say they always or nearly always adopt a working position (sitting at a desk or table) when using their tablet (versus $64 \%$ of respondents using laptops). This first study suggests that internet users are usually sitting on a couch when they are using their tablet, rather than at a table. 
The second pilot study was an observational study. Ten users of digital tablets were summoned to the home of the researcher. These users were selected from the social circle of the researcher to represent a range of ages and different body types. Each participant came to the home of the researcher with his/her digital tablet. He/she was shown into the living room/dining room, a room with a living area (couch, coffee table) and a dining area (table and chairs). The respondent received the instruction to sit wherever he/she wished to answer a survey on his/her digital tablet. All 10 respondents spontaneously went to the couch. They adopted two types of positions : 6 of them held the tablet flat (this position will be described as near-horizontal in the rest of the study), resting on the knees, hands, or even sometimes the respondent's bag, and 4 of them held the tablet slightly inclined (this position will be described as near-vertical in the rest of the study), with the tablet resting on the raised legs, the hands, or the tablet easel (figure 3).

\section{-Figure 3 -}

After these two pilot studies, we selected two positions on which to test the research hypotheses: the so-called "near-horizontal" position (the screen forms an angle with the ground of less than $45^{\circ}$, it is nearly parallel with the ground, and the internet user's gaze is looking downward) and the so-called "near-vertical" position (the screen forms an angle with the ground of greater than $45^{\circ}$, it is nearly perpendicular to the ground and the gaze is toward the front) (figure 3). In these two positions, the users are seated on a sofa. These positions have the advantages of maintaining the same observation distance from the screen (approximately $35 \mathrm{~cm}$ ). This distance corresponds to the ideal observation distance (also called orthoscopic distance) for a tablet with a ten-inch 
$\operatorname{screen}^{1}(17 \times 24 \mathrm{~cm})$. These two positions also have the advantage of placing the screen against a static and neutral background (i.e. the user's pants), which does not distract attention from the screen. The literature on visual saturation has emphasized the extent to which the visual elements located near the target of the eyes can create interference and disturb perception (Janssens et al, 2012; Greenberg, 2012; Whitney and Levi, 2011).

\section{Study 1}

Design of study 1.

The purpose of the first experimental study was to select an advertisement using a photograph with a particular perspective and to study whether the position in which the internet user holds the tablet (so-called "near-vertical position", so-called "nearhorizontal position" - see figure 3) has an impact on mental simulation of the product and on advertised product purchase intention. Two experimental conditions were selected based on the position in which the internet user was placed and each respondent was assigned randomly to one of the two conditions (near-vertical position or nearhorizontal). A between-subject design was selected, and each respondent adopted only one position.

Selection of the advertisement for study 1.

For this study, we selected a photograph of a product using a front-view perspective on the product (the camera is placed in front of the product).

In the frontal perspective, the plane of the photograph is vertical (figure 3). With a photograph in a front-view perspective, the position of the tablet allows the viewer to

\footnotetext{
${ }^{1}$ The respondents all used full-size tablets of approximately ten inches.
} 
align his head posture with the perspective of the picture when he holds the device in a near-vertical position.

We decided to use an advertisement on a new kitchen utensil (a kit used to store liquids, such as yogurt drinks) that evokes grasping representation relatively automatically (appendix 1). Indeed, mental simulation processes are more easily activated when the advertisement depicts a product for which usage is easy to understand (Zhao et al, 2011).

The photograph was displayed in $11 \mathrm{~cm} \times 15 \mathrm{~cm}$ on the tablet. We took care to position the photograph in the center of the screen because unusual positions on the screen can enhance (or decrease) the attention of internet users and consequently change their reactions to the advertisement (Janssens et al, 2012). The image was static so as not to distract the internet users (Simola et al, 2011)

\section{Sample of study 1.}

The study was administered to 76 users of digital tablets recruited through an announcement posted in the hallway of a French university. The respondents were not compensated. 32 respondents were randomly assigned to a "near-vertical tablet" condition and 44 respondents were assigned to a "near-horizontal tablet" condition. The respondents were between 14 and 63 years of age and the ages were fairly well distributed between the two experimental conditions (Mhoriz. $=35$ years old; Mvert. $=$ 40 years old). The data sheet administered at the end of the survey indicates that the respondents use their digital tablet frequently and that there is no major difference in usage between the two groups (Mhoriz. $=5.3$; Mvert. $=4.8 ; \mathrm{p}=0.162$ ).

Study 1 procedure. 
The survey was sent by e-mail. In the e-mail invitation, respondents were informed that they had to spend five minutes seated on a couch without being disrupted, moving, or changing position. Depending on the position to which they were assigned, they were asked to hold their tablet flat in a "near horizontal position" or in a "near-vertical position". The device positon and the body posture that they had to adopt during the study was illustrated by a picture (figure 3). They were given the instruction to assume the same position as the person in the picture.

During the survey, reminders were regularly displayed: "we remind you that it is essential that you remain in the same position when answering this survey." At the beginning of the survey, the respondent agreed to remain in this same position for the entire survey by checking the item "I agree to maintain this position for the entire duration of the survey."

\section{Selection of measurements for study 1.}

To measure how much mental simulation process was activated in viewers' mind, we built on previous literature on mental simulation and mental imagery. Indeed, mental simulation measures are inspired by mental imagery scales (e.g. Schlosser, 2003; Choi and Taylor, 2014).

There are various correlated indicators of the degree of mental simulation elicited by the message. Mental simulation process can be measured by asking questions that refer to the quantity of mental images that are activated by the stimuli (study 3, Elder and Krishna, 2012) or by questions that refer to the ease of the mental simulation process (study 4, Elder and Krishna, 2012). Indeed, various studies on mental imagery demonstrate that ease and quantity of mental imagery are strongly correlated (for a 
review see Babin et Burns, 1998). For example, mental imagery research of Bone and Ellen (1992) empirically shows that the quantity and ease items load together.

In this paper, the items to measure mental simulation process focus on ease of the mental simulation process. Indeed, it may be more difficult for respondents to evaluate the quantity of mental images process than the easiness of the mental simulation process. It seems easy for respondents to evaluate if mental simulation with advertised product came easily to mind, or if they felt that mental interaction with the advertised product was very demanding. To the contrary, as the mental simulation process is a narrative and continuous process (Escalas, 2007), it may be more difficult for respondents to give an evaluation of the number of mental images processed when they were exposed to the advertisement. Therefore, we chose in this paper, to measure mental simulation process by focusing on ease of the mental simulation process.

We therefore asked the respondents to note on a 7-point scale, To what extent it was difficult to imagine using the product (from extremely difficult to extremely easy), and How much time did it take you to imagine using the product (from a very long time to very quickly). The respondents also evaluated whether they were in agreement with the statement It took effort of thought to imagine myself using the product (from entirely agree to entirely disagree). These three elements were combined to form a measurement of mental simulation $(\alpha=0.818)$.

To measure behavioral intentions with regard to the object shown in the advertisement, we asked the respondents to rate "the probability that they would buy this product".

\section{Results of study 1}

As an initial step, we also tested whether intent to buy and mental simulation varied according to screen position. We performed a difference of means test between the two 
experimental conditions and the mental simulation and intent to purchase variables. The test indicates that mental simulation is easier when the tablet is in the near-vertical position, in other words, when it is aligned with the frontal perspective of the image (versus a tablet in a near-horizontal position) $($ Mhoriz. $=3.15$; Mvert. $=4.05$; $F(1,74)=5.71 ; p=0.019)$. The respondents more easily imagined themselves using the product when holding their tablet in a position that allowed them to align their body posture with the perspective of the advertisement (in this study, a frontal view/frontal perspective).

With regard to intent to buy, the test also indicates that a near-vertical tablet position leads internet users to form a more favorable purchase intention than a near-horizontal tablet position $($ Mhoriz. $=1.45 ;$ Mvert. $=2.21 ; \mathrm{F}(1 ; 74)=8.30 ; \mathrm{p}=0.005)$. Therefore, online advertising creates greater purchase intention when viewed on a tablet held in a position that allows the user to align his/her body posture with the perspective of the image. $\mathrm{H} 1$ is validated for an advertisement with a frontal perspective.

\section{-Table 1 -}

To test the link between mental simulation and purchase intention, we performed a linear regression between the two variables. The analysis indicates that the regression of mental simulation on purchase intention is significant $(b=0.31 ; \mathrm{SE}=3.61 ; \mathrm{p}<0.001)$.

Thus, the more the respondents could easily imagine themselves using the product, the more they reported that they wanted to buy the product.

To test the mediating effect of mental simulation, we followed the method recommended by Hayes and Preacher (2013) and performed a simple mediation test using a bootstrapped procedure (Model 4, n=1000), in which we set purchase intention as the dependent variable, tablet position as the independent variable, and mental simulation as the mediating variable. Results indicated that tablet position was a 
significant predictor of mental simulation and that mental simulation was a significant predictor of purchase intention. These results support the mediational hypothesis. Tablet position was no longer a significant predictor of purchase intention after controlling for mental simulation, consistent with full mediation. The indirect effect was tested using a bootstrap estimation approach with 1000 samples. These results indicated the indirect coefficient was significant, $b=-0.191,95 \% \mathrm{CI}=-0.5610,-0.0187$. The effect of mediation of mental simulation is significant with mental simulation averages that exclude zero and a confidence interval of $95 \%$ [-0.5610; -0.0187$]$. H3 is validated for an advertisement with a frontal perspective.

\section{-Table 2 -}

\section{Discussion of study 1 .}

This first experimental study confirms that the position in which the tablet is held can affect behavioral intentions toward online advertising. However, in this stage of the research, the role of consistency between image perspective and tablet position has not been demonstrated. The hypothesis was made that a tablet position enabling alignment of the body posture with the perspective of the photograph would increase mental simulation and purchase intention. But at this stage of the research, some may argue that the orientation of the head downward could have provoked more negative reactions than an upward head. In fact, following the work of Van Kerckhove, Geuens, and Vermeir (2015) on gaze orientation and level of thought, some might say that looking downward leads one to adopt more concrete thinking, which encourages the individual to focus on the negative elements of the product (White et al, 2011). Indeed, different points of views could convey various associations of ideas. A study conducted in 2012 by 
Schuldt, Konrath and Schwarz demonstrated that the viewing angle of photographs of cars impacted the assessment of the product and characteristics related to power. As a result of this work, holding the device horizontally and adopting a high-angle view could increase the impression of dominating one's environment and thus decrease preferences for low-value products (such as the kitchen aid product depicted in the study 1 advertisement).

Therefore, in order to demonstrate the role of consistency of viewers' body posture and image perspective, we conducted a second experimental study in which we simultaneously manipulated tablet position (near-horizontal, near-vertical) and image perspective (front-view, birds' eye view).

\section{Study 2}

Design and procedure for study 2.

We implemented a study in which the same advertised product is photographed from two different perspectives: a front-view perspective and a high-angle perspective. We selected an advertisement showing a cup of coffee. In the front-view perspective, the cup of coffee is photographed from the front. In the high-angle perspective, the cup of coffee is photographed from the top. We verified that, in all four conditions, the image was easy to understand and that information in the advertisement was easy to process $(1.4<\mathrm{M}<1.6 ; \mathrm{ps}>0.495)$. To do so, we used two 7 points Likert scale items and calculated an average score of the two items: (understanding this image requires effort of thought and to understand this image, you have to concentrate).

The experimental design includes four different conditions (near-vertical, nearhorizontal) x (front-view, birds' eye view). A between-subject design was selected, and each respondent viewed only one image in a single position. 
The survey was sent by e-mail, and the procedure was exactly the same as for study 1 .

\section{- Table 3 -}

\section{Measurements of study 2.}

We adapted the measurements from the first study to the context of study 2 . The respondents had to indicate on a 7-point scale, To what extent they imagined drinking the coffee (from not at all to a lot), How much time it took them to imagine drinking coffee (from a very long time to very quickly). To what extent it was easy to imagine the taste of coffee and To what extent they were immersed in the image of the coffee (from not at all to a lot). These four items were combined to form a mental simulation measurement ( $\alpha=0.693)$.

To measure the behavioral intentions with regard to the object shown in the advertisement, we used three items in combination to create a measurement of approach behavior. The respondents were asked to note the probability that they would take a coffee break?, that they would take a moment to have a coffee? They also had to respond using the following Likert scale: I feel like having a cup of coffee $(\alpha=0.805)$.

Sample of study 2.

We recruited users of digital tablets who agreed to participate in an online survey by posting an announcement in the hallways of a French university. The participants were assigned randomly to the four conditions. This procedure resulted in the collection of 74 completed surveys, of which 37 respondents were exposed to the image in a frontal 
perspective and 49 in a high-angle perspective. Forty respondents were women and thirty-four respondents were men. The average age of the respondents is 32 .

There was no difference in terms of familiarity with digital tablets and general attitudes towards the experimental stimuli. On average, in all four conditions, the respondents used their digital tablets fairly often $(1.7<\mathrm{M}<2.5$; $\mathrm{ps}>0.115)$. In all four conditions, the respondents moderately enjoy drinking coffee $(2.20<\mathrm{M}<3.20$; ps $>0.070)$.

\section{- Table 4-}

\section{Results of study 2.}

In order to study whether the consistency between the perspective of the advertising image (frontal, high-angle) and the screen position (vertical, horizontal) facilitated mental simulation and increased purchase intention, we conducted two tests of analysis of variance with interaction. The purchase intention and mental simulation were introduced in the model as dependent variable. The device position (near-horizontal, near-vertical position) and the ad perspective (frontal perspective, high-angle perspective) were set as the independent interacting variables.

First, the analysis indicates that there is no main direct effect of device position and image perspective on purchase intention and on mental simulation $(\mathrm{p}>0.05)$. Second, there is a significant interaction between the position of the tablet and the perspective of the advertising image $(\mathrm{F}(3 ; 70)=5.857, \mathrm{p}=0.001$ for purchase intention and $\mathrm{F}(3 ; 70)=3.560, \mathrm{p}=0.018$ for mental simulation $)$. 
The contrast analysis indicates that the advertisements shot from a front-view perspective reduces mental simulation of the product when viewed on a screen in the horizontal position (versus vertical) (Mhoriz. $=2.91$; Mvert. $=4.20 ; \mathrm{p}=0.04$ ). Furthermore, it triggers less purchase intention when viewed on a screen in the horizontal position (versus vertical) $($ Mhoriz. $=2.43$; Mvert. $=3.93 ; \mathrm{p}=0.06$ ). Thus, when the advertisement is from a front-view perspective, the perspective consistency between the advertisement and the viewer's body posture increases mental simulation and creates stronger purchase intention.

However, the results are more nuanced for advertisements with a high-angle perspective. They trigger less intent to buy when viewed on a screen in the vertical position (versus horizontal) $($ Mhoriz. $=3.02$; Mvert. $=1.96 ; \mathrm{p}=0.019)$. However, the mental simulation is not significantly impacted by the position of the screen (Mhoriz. $=$ 3.17; Mvert. $=3.72 ; \mathrm{p}=0.186)$. Therefore, holding the screen in a position that allows viewers to align their body posture with the perspective of the image increases purchase intention for the two tested perspectives but only increases mental simulation for the front-view perspective. $\mathrm{H} 2$ is validated, but $\mathrm{H} 1$ is only partially validated for images with a frontal perspective.

\section{- $\quad$ Figure 4-}

We conducted a regression analysis using the Hayes and Preacher (2013) macro in order to examine whether mental simulation mediates the positive effect of perspective consistency on purchase intention. To do so, we created a perspective consistency variable (yes, no) in which the frontal (high-angle) image viewed on a position in near- 
vertical (near-horizontal) position was consistent in terms of perspective. Results indicated that perspective consistency was a significant predictor of mental simulation, $\mathrm{b}=-0.31, \mathrm{SE}=0.13, \mathrm{p}<.05$, and that mental simulation was a significant predictor of purchase intention, $\mathrm{b}=0.80, \mathrm{SE}=0.11 \mathrm{p}<.05$. These results support the mediational hypothesis. Perspective consistency was no longer a significant predictor of purchase intention after controlling for the mediator, mental simulation, $\mathrm{b}=0.0008, \mathrm{SE}=0.13$, ns, consistent with full mediation. The indirect effect was tested using a bootstrap estimation approach with 5000 samples. These results indicated the indirect coefficient was significant, $\mathrm{b}=-0.25, \mathrm{SE}=0.13,95 \% \mathrm{CI}=-0.5437,-0.0355$. In fact, zero is not included in the confidence interval $[-0.5437 ;-0.0355]$. The results indicate that mental simulation mediates the effect of perspective consistency on purchase intention. H3 is validated.

- Table 6 -

\section{Discussion of study 2.}

Study 2 shows that purchase intention for an online advertised product is higher when the advertisement is seen on a mobile device that is held in a position that allows the viewers to stand in a body posture that is consistent with the product image perspective within the advertisement. Therefore, purchase intention for front-view advertisement is increased when the mobile device is held in a near-vertical position. Conversely, purchase intention for high-angle perspective (birds' eye view) is higher when the mobile device is held in a near-horizontal position.

Study 2 also demonstrates that this positive consistency effect is mediated by mental simulation processes. Indeed, consistency between viewers' body posture and image 
perspective results in increase mental simulation, which in turn results in higher purchase intention. Results also suggest that inconsistency between body postures and image perspective is less impactful for high-angles perspectives (birds' eye view). Indeed, although front-view advertisements lead to lower mental simulation process when it is seen on a device held in a near-vertical position, mental simulation is not significantly and negatively impacted by the mobile device position when the advertisement depicts a high-angle product perspective. For high-angle perspectives, consistency between the position and the perspective of the image does not have any significant impact on mental simulation. This is consistent with previous studies on mental simulation processes triggered by the verticality of images. Indeed, Royo-Vela and Black (2018) show that images pictured from high-angle perspective have a greater effect on the viewer than images produced at ground level. This explains why, in study 2, mental simulation was not disrupted by tablet position when the perspective of the image is high angle.

\section{CONCLUSION}

Both studies that we conducted confirm that the impact of commercial photographs on internet users depends on the position of the mobile screen on which the photographs are viewed. Although we might expect that individuals would gradually become accustomed to processing the images on their mobile device regardless of the position and their actual body posture, this is not the case. Advertisements showing products from a high-angle perspective trigger stronger purchase intention if they are shown on a screen held near-horizontally. To the contrary, advertisements showing products with a 
front-view perspective result in higher purchase intention when the device is held in a near-vertical position.

The results thus contribute to mobile marketing research by showing that the effectiveness of a visual advertisement is improved when the image is viewed on a device held in a position that allows viewers' body postures (downward position, frontward position) to be consistent with the perspective of the advertising image (downward position for vertical perspective ad, frontward position for frontal perspective ad).

These results extend the perceptual-motor compatibility principle (Förster, 2004) by showing that approach behavior toward advertised products are easier to activate when the mobile device is held in a position that is consistent with the image perspective. Perspective consistency helps the viewers to generate mental simulation of the product, which consequently has a positive effect on purchase intention. In frontal views advertisements, where the products are shot with the cameras are positioned in front of them, the mental movement needed to mentally grasp the products are frontward movements; they are easier to activate when the mobile device is held vertically because the viewers hold their heads straight, looking in front of them.

Although mental simulation mediates, for both types of perspective (front-views and high-angle views), the impact of body posture and image perspective on purchase intention, we find in this study that the device position does not have a significant impact on mental simulation for high-angle perspective advertisements. Previous research has shown that an advertisement with a high-angle perspective can engender surprise, entertainment, and potentially positive emotions (Royo-Vela and Black, 2018). The literature on non-canonical perspectives (Kosslyn, Thompson and Alpert, 1999) 
points to the roles of surprise, attention, and commitment. Yet, when attention is higher, interferences have lower negative effects on individuals (Reed et al, 2017). Therefore, inconsistency between body posture and image perspective could be less impactful for high-angle images than for front-views images because viewers benefit from higher available cognitive resources to control the negative effect of inconsistency between their body posture (frontward head position) and image perspective (high-angle perspective).

This research extends the literature on the impact of digital interfaces on advertising efficacy (Brasel and Gips, 2014; Shen et al, 2016). This paper contributes to a better understanding of mental simulation processes on images displayed on a mobile screen. Very few research demonstrate empirically that mental simulation with advertised products on mobile happens spontaneously and drives products evaluation and intention to buy (Zhao et al, 2011). Usually mental simulation is considered to happen when a specific priming message such as "Imagine yourself interacting with the product" is proposed to consumers. Yet, we demonstrate in this paper that mobile advertising leads to spontaneous generation of mental simulation process, even if there is no priming, and that mobile device inclination modifies purchase intention toward advertised products. Based on the literature on embodied cognition and advertisement effectiveness (e.g. Elder and Krishna, 2012), this research establishes a link between viewers' body postures and purchase intention, without mobilizing attitudes. An avenue for future research will be to examine what attitudinal mechanisms are at work when the advertisement image is shot from a high-angle perspective. A link between perspective consistency and the emotional reactions of internet users will have to be explored.

\section{Limits and future avenues of research}


This study also have several limits that are also potential future avenues of research. First, viewers' familiarity with the advertisements have not been controlled. Yet, the two advertisements present objects that evoke grasping representations relatively automatically. But there is still work to be done to understand the role of product previous knowledge on mental simulation processes and their impact on purchase intentions (Zhao et al, 2011).

Second, potential hand proximity effects have not been explored. Research shows that attentional resources are more focused and have a finer grain near the hands (Reed et al, 2017). In particular, because of this hand proximity effects, where perception and attention is higher, interference effects are shown to be lower proximal to the hands (Reed et al, 2017). Yet, we did not control how the viewers' put their hands on the mobile device to hold it. Negative impact of inconsistency between perspective and body postures could have been lower for viewers that held their screens in their hands, in comparison to those who let their screen on their knees. This hand proximity effect should be investigate in the future so as to better understand the role of viewers' body postures on mobile advertising effectiveness.

\section{Managerial implications}

This research encourages marketing to take into account the position in which the screen is viewed. Tablets and smartphones are already equipped with a gyroscope to measure the orientation of the tablet. The question of image perspective arises and certain websites have recently decided to systematically offer several views of the product $^{2}$ in order to give internet users multiple perspectives on the product. These initiatives currently do not take into consideration the position of the mobile screen, but

\footnotetext{
${ }^{2}$ Like the jeweler James Allen, who provides the opportunity to view the product from all angles 
the first signs of questioning concerning online image perspective suggests that this research could quickly resonate with publishers of websites. In particular, pre-existing "web responsive design" practices could be supplemented by introducing the option to adapt product photographs to the orientation of the viewing screen (e.g. horizontal, vertical). Automatically adjusting the photograph of the product to the angle of the screen could maximize the effectiveness of online advertising.

In order to increase the external validity of this research, this work should be replicated on mobile phones. Although marketing resistance of mobile phones is increasing, with the popularity of programs blocking advertisements (such as Adblock Plus), mobile marketing on smartphones affects more than 7 billion people around the world. It would also be interesting to replicate this work using video, a format that is growing rapidly on mobile devices. In conclusion, this initial research is an invitation to further investigation into the interaction between content displayed on the internet and the position in which mobile screens are viewed. 


\section{REFERENCES}

Babin Laurie A. and Burns Alvin C. (1998), “A Modified Scale for the Measurement of Communication-Evoked Mental Imagery”, Psychology \& Marketing, 15(December), 261-278.

Barsalou Lauwrence, W. (2008), “Grounded cognition”, Annual Review of Psychology, $59,617-45$.

Bart Yacov, Andrew T. Stephen., Miklos Sarvary (2014), "Which products are better suited to mobile advertising? A field study of mobile display advertising effects on consumer attitudes and intentions", Journal of Marketing Research, 51 (June), 270-285.

Bone Paula F., Pam S. Ellen (1992), "The generation and consequences of communication-evoked imagery”, Journal of Consumer Research, 19 (June), 93-104.

Brasel Adam S and Gips James (2014), Tablets, touchscreens, and touchpads: How varying touch interfaces trigger psychological ownership and endowment, Journal of Consumer Psychology 24 (2), 226-233

Chao Linda L., Alex Martin (2000), "Representation of Manipulable Man-Made Objects in the Dorsal Stream" NeuroImage, 12 (March), 478-84.

Chandler Scott B. (2001), "Comparing the legibility and comprehension of type size, font selection and rendering technology of onscreen type", Doctoral Dissertation, Virginia Polytechnic Institute and State University,Blacksburg,

Choi Yung K., Jang-Sun Hwang, Sally Mcmillan (2008), “Gearing up for mobile advertising : a cross-cultural examination of key factors that drive mobile messages home to consumers", Psychology and Marketing, 25 (August), 756-768. 
Choi Yung K., Charles R. Taylor (2014), "How do 3-dimensional images promote products on the internet?", Journal of Business Research, 67 (October), 2164-2170.

Elder Ryan S., Aradhna Krishna (2012), "Visual Depiction Effect in Advertising:

Facilitating Embodied Mental Simulation through Product Orientation”, Journal of Consumer Research, 38 (April), 988-1003.

Escalas Jennifer E. (2004), "Narrative Processing: Building Consumer Connections to Brands," Journal of Consumer Psychology, 14 (June), 168-179.

Escalas Jennifer E. (2007), “Self-Referencing and Persuasion: Narrative Transportation versus Analytical Elaboration”, Journal of Consumer Research, 33 (March), 421-429

Förster Jens, (2004), “How body feedback influences consumers' evaluation of product", Journal of consumer psychology, 14 (December), 416-426.

Greenberg Adam S. (2012), “The Role of Visual Attention In Internet Advertising",Journal of advertising research, 52, (December), 400-404.

Gregory Larry W., Robert B. Cialdini, Kathleen M.Carpenter (1982), “Self-Relevant Scenarios as Mediators of Likelihood Estimates and Compliance: Does Imagining Make It So?”, Journal of Personality and Social Psychology, 43 (July), 89-99.

Ha Imsook, Youngseog Yoon, Munkee Choi (2007), “Determinants of adoption of mobile games under mobile broadband wireless access environment", Information and Management, 44 (April), 276-286.

Hayes Andrew F., Kristopher J. Preacher (2013), “Statistical Mediation Analysis with a Multicategorical Independent Variable", British Journal of Mathematical and Statistical Psychology, 67 (November), 451-70. 
Hansraj, KK (2014), Assessment of stresses in the cervical spine caused by posture and position of the head, Surg Technol Int., 25, 277-9

Hsu Chin-Lung, His-Peng Lu, Hueig-Hsia Hsu (2007), “Adoption of the mobile Internet: an empirical study of multimedia message service (MMS)", Omega, 35 (December), 715-726.

Janssens Wim, Patrick De Pelsmacker, Maggie Geuens (2012), “Online advertisements and congruency effects: it depends on how you look at it", International journal of advertising, 31 (Spring), 579-60

Jeong Eun Ha and Soo Cheong Shawn Jang (2016). "Imagine yourself being healthy: the mental simulation effect of advertisements on healthy menu promotion." International Journal of Hospitality Management, 53, 81-93.

Jessen Tanja Lund, Paul Rodway (2010, “The effects of familiar and unfamiliar adverts on selective attention", Perceptual and Motor Skills, 110 (June), 941-960

Jiang Yuwei, Rashmi Adaval, Yael Steinhart, Robert S. Wyer Jr. (2014), “Imagining Yourself in the Scene: The Interactive Effects of Goal-Driven Self Imagery and Visual Perspectives on Consumer Behavior". Journal of consumer research, 41 (August), 418435.

Klein Lisa R. (2003), “Creating virtual product experiences: The role of telepresence”. Journal of Interactive Marketing, 17 (January), 41-55.

Kosslyn Stephen M., William L. Thompson; Nathaniel M. Alpert (1997), “Neural Systems Shared by Visual Imagery and Visual Perception: A Positron Emission Tomography Study", Neuroimage, 6 (April), 320-334. 
Lombard Matthew, Ditton Theresa (1997), “At the heart of it all: The concept of presence", Journal of Computer-Mediated Communication, 3 (September)

Madzharov Adriana V., Lauren G. Block, Maureen Morrin (2015), “The Cool Scent of Power: Effects of Ambient Scent on Consumer Preferences and Choice Behavior". Journal of Marketing, 79 (January), 83-96.

Moon Ji-Won, Young-Gul Kim (2001), "Extending the TAM for a world-wide-web context”. Information \& Management, 38 (February), 217-230.

Muter Paul, Paula Marutto P. (1991) "Reading and skimming from computer screens and books: the paperless office revisited?", Behaviour and Information Technology, 10 (July), 257-266.

Nielsen Jesper H., Jennifer Edson Escalas (2010), "Easier is not always better: the moderating role of processing type on preference fluency". Journal of consumer psychology, 20 (July), 295-305.

Nowlis Stephen M., Baba Shiv (2005), “The Influence of Consumer Distractions on the Effectiveness of Food-Sampling Programs”, Journal of Marketing Research, 42 (May), $157-68$

Nathan Novemsky, Ravi Dhar, Norbert Schwarz, Itamar Simonson (2007), "Preference Fluency in Choice”. Journal of Marketing Research, 44 (August), 347-356

Patel Dev, Jeremy Schneider, Kushan Surana (2013), "Cracking the Mobile Advertising Code", Harvard Business Review (September)

Reed Catherine L., Clay Summer N., Kramer Abigail O., Leland David S., Hartley Alan A. (2017), “Attentional Effects of Hand Proximity Occur Later in Older Adults: 
Evidence From Event-Related Potentials", Psychology and Aging, 32 (August), 710721.

Schlosser Ann E. (2003), "Experiencing Products in the Virtual World: The Role of Goal and Imagery in Influencing Attitudes versus Purchase Intentions”, Journal of Consumer Research, 30 (September), 184-198.

Schuldt Jonathon P., Sara H. Konrath, Norbert Schwarz (2012), “The Right Angle: Visual Portrayal of Products Affects Observers' Impressions of Owners”, Psychology and Marketing, 29 (September), 705-711.

Schwarz Norbert (2004), "Metacognitive Experiences in Consumer Judgment and Decision Making”. Journal of Consumer Psychology, 14 (September), 332-348.

Shankar Venkatesh, Sridhar Balasubramanian (2009), "Mobile Marketing: A Synthesis and Prognosis”, Journal of Interactive Marketing, 23 (May), 118-129.

Shen Hao, Jiang Yuwei, Rashmi Adaval (2010), "Contrast and Assimilation Effects of Processing Fluency”, Journal of Consumer Research, 36 (February), 876-889.

Shen Hao, Zhang Meng, Krishna Aradhna (2016), “Computer Interfaces and the "Direct-Touch" Effect: Can iPads Increase the Choice of Hedonic Food?", Journal of Marketing Research, 53 (October), 745-758.

Shiv Baba, Stephen M. Nowlis (2004), “The Effect of Distractions While Tasting a Food Sample: The Interplay of Informational and Affective Components in Subsequent Choice”, Journal of Consumer Research, 31 (December), 599-608. 
Simola Jaana, Jarmo Kuisma, Anssi Öörni, Jukka Uusitalo (2011), “The impact of salient advertisements on reading and attention on web pages". J. Exp. Psychol. Appl. 17 (June), 174-190.

Tinker Miles A (1956), "Effect of sloped text upon the readability of print". Optometry and vision science, (April), 33-189.

Tsang Melody, Shu-Shung Ho, Ting-Peng Liang (2004), “Consumers attitude toward mobile advertising: an empirical study", International Journal of Electronic Commerce, 8, 3 (Spring), 65-78.

Van Kerckhove Anneleen, Maggie Geuens, Iris Vermeir (2015), “The Floor Is Nearer than the Sky: How Looking Up or Down Affects Construal Level”, Journal of Consumer Research, 41 (April), 1358-1371.

Van Rompay, T., de Vries P. W., Bontekoe F (2012), “Embodied Product Perception: Effects of Verticality Cues in Advertising and Packaging Design on Consumer Impressions and Price Expectations.” Psychology \& Marketing, 29 (November), 919928.

Vasavada AN, Nevins DD, Monda SM, Hughes E, Lin DC (2015), “Gravitational demand on the neck musculature during tablet computer use", Ergonomics, 58 (February), 990-1004.

Royo-Véla Marcelo, Black Matthew (2018), Drone images versus terrain images in advertisements: Images' verticality effects and the mediating role of mental simulation on attitude towards the advertisement, Journal of marketing communications, in press. 
Weijing Xie, Zhao Yunze, Xie Wenya (2013), “The effect on interface design on handheld devices on mobile advertising effectiveness among college students in China", International Journal of Mobile Marketing, 8 (Summer), 46-60.

Winkielman Piotr, John T. Cacioppo (2001), "Mind at Ease Puts a Smile on the Face: Psychophysiological Evidence That Processing Facilitation Elicits Positive Affect", Journal of Personality and Social Psychology, 81 (December), 989-1000.

White Katherine, Rhiannon MacDonnell, Darren W. Dahl (2011), “It's the Mind-Set that Matters: the role of construal level and Message Framing in influencing consumer efficacy and conservation Behaviors", Journal of Marketing Research, 48 (June), 472485.

Whitney David, Dennis M. Levi 2011), "Visual Crowding: A Fundamental Limit on Conscious Perception and Object Recognition", Trends in Cognitive Sciences, 15 (April), 160-168.

Xu, David Jinjung (2006), "The influence of personalization in affecting consumers attitudes toward mobile advertising in China", Journal of Computer Information Systems, 47 (December), 9-19.

Young Justin G., Matthieu Trudeau, Dan Odell, Kim Marinelli, Jack T. Dennerlein (2012), “Touch-screen tablet user configurations and case-supported til taffect head and neck flexion angles”, Work, 41 (January), 81-91.

Chian-Son Yu, Wachara Chantatub (2016), “Consumers' resistance to using mobile banking: evidence from Thailand and Taiwan”, International Journal of Electronic Commerce Studies, 7 (May), 21-38. 
Zhao Min, Hoeffler Steve, ZauberMan Gal (2011), "Mental Simulation and Product evaluation: the affective and Cognitive Dimensions of Process versus outcome Simulation", Journal of Marketing Research, 48 (October), 827 -839.

Zhou Tao (2013), "The effect of flow experience on user adoption of mobile TV", Behaviour \& InformationTechnology, 32 (January), 263-272. 


\section{FIGURES AND TABLES}
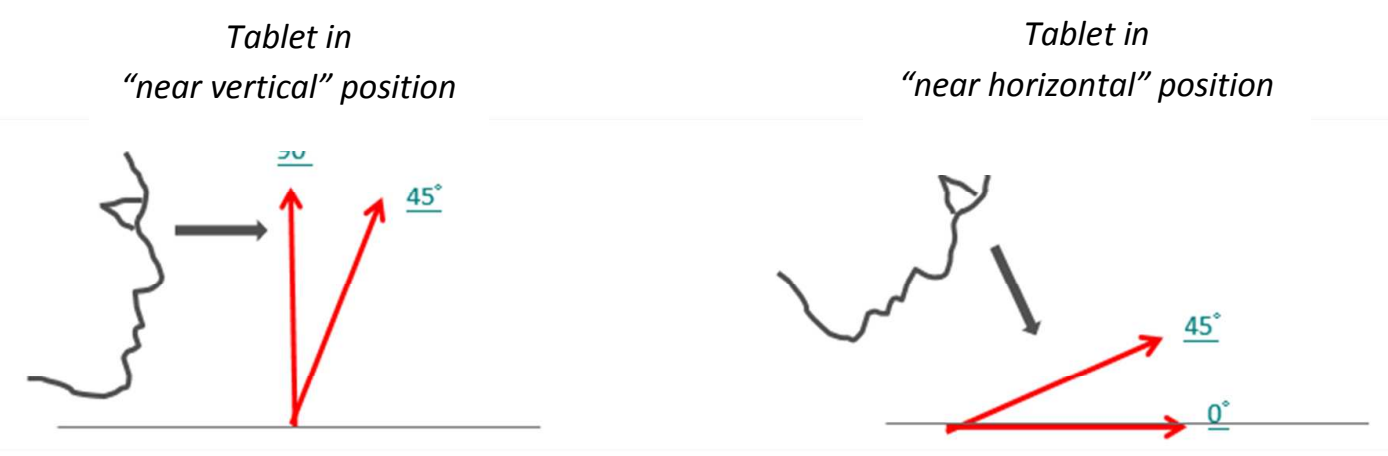

Figure 1: Impact of mobile devices body postures on purchase intention of online advertised products

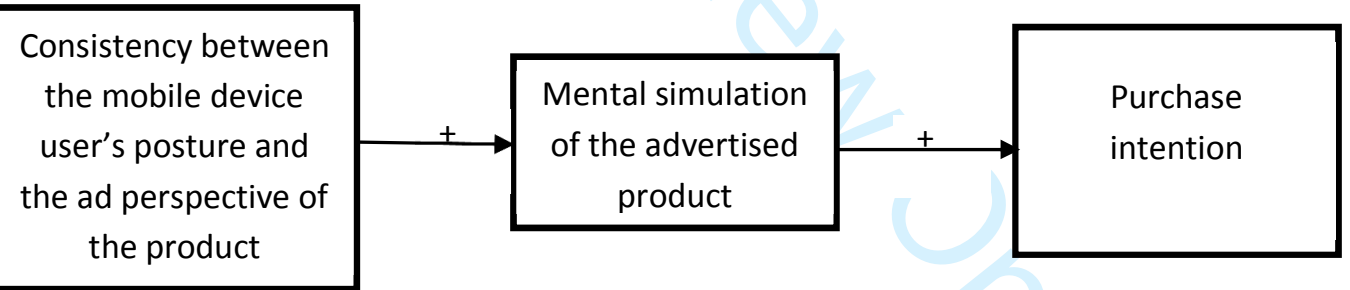

Figure 2. Conceptual research model 
Tablet in near-

vertical position

(frontal view $<45^{\circ}$ )

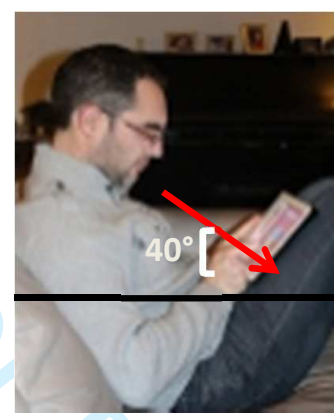

Tablet in near-

horizontal position

(high-angle view $>45^{\circ}$ )

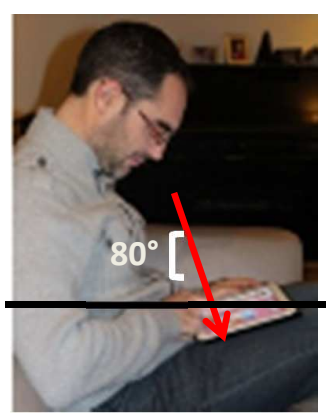

Figure 3: Positions spontaneously adopted by users of digital tablets

\begin{tabular}{|l|l|l|l|}
\hline Experimental condition & Participants & simulation & intention \\
\hline Tablet in near-vertical & 44 & 3.15 & 1.45 \\
position & & & \\
\hline Tablet in near horizontal & 32 & 4.05 & 2.21 \\
position & & & \\
\hline
\end{tabular}

Table 1: Position of the tablet, mental simulation, and purchase intention (study 1) 
Study 1: Indirect effect of tablet position on purchase intention

\begin{tabular}{lllll}
\hline Antecedent & Mediator & Effect & 95\% LLCI & 95\% ULCI \\
\hline Tablet & Mental & -0.191 & -0.561 & -0.019 \\
position & simulation & & &
\end{tabular}

Table 2: Mediation of mental simulation on purchase intention (study 1)

\begin{tabular}{|l|l|l|}
\hline 4 conditions & Position & Position \\
\hline High-angle perspective & near-vertical & Consizontal \\
\hline & Inconsistency of perspective & Consistency of perspective \\
\hline Frontal perspective & & \\
\hline & Consistency of perspective & Inconsistency of \\
\hline
\end{tabular}

Table 3: Experimental design of study 2 


\begin{tabular}{|c|c|c|c|}
\cline { 2 - 4 } \multicolumn{1}{c|}{} & $\begin{array}{c}\text { Total } \\
\text { participants }\end{array}$ & $\begin{array}{c}\text { Frontal } \\
\text { perspective } \\
\text { image }\end{array}$ & $\begin{array}{c}\text { High-angle } \\
\text { perspective } \\
\text { image }\end{array}$ \\
\hline $\begin{array}{c}\text { Near vertical } \\
\text { position }\end{array}$ & 38 & 15 & 23 \\
\hline $\begin{array}{c}\text { Near horizontal } \\
\text { position }\end{array}$ & 36 & 20 & 16 \\
\hline
\end{tabular}

Table 4: Sample of study 2

\begin{tabular}{|c|c|c|c|}
\hline & & $\begin{array}{l}\text { Frontal } \\
\text { perspective }\end{array}$ & $\begin{array}{l}\text { High-angle } \\
\text { perspective }\end{array}$ \\
\hline \multirow{2}{*}{$\begin{array}{l}\text { Purchase } \\
\text { intention }\end{array}$} & $\begin{array}{l}\text { Near-vertical } \\
\text { position }\end{array}$ & 3.9333 & 1.9565 \\
\hline & $\begin{array}{l}\text { Near-horizontal } \\
\text { position }\end{array}$ & 2.4286 & 3.0185 \\
\hline \multirow{2}{*}{$\begin{array}{l}\text { Mental } \\
\text { simulation }\end{array}$} & $\begin{array}{l}\text { Near-vertical } \\
\text { position }\end{array}$ & 4.2000 & 3.1667 \\
\hline & $\begin{array}{l}\text { Near-horizontal } \\
\text { position }\end{array}$ & 2.9125 & 3.7188 \\
\hline
\end{tabular}

Table 5: Tablet position, mental simulation, and behavior (study 2) 
Buying intention

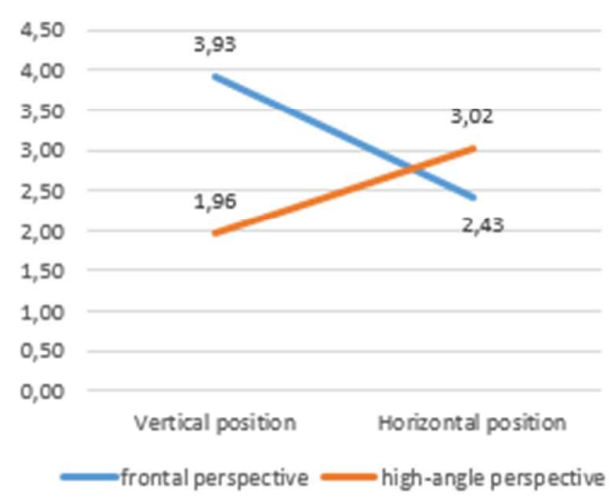

Mental simulation

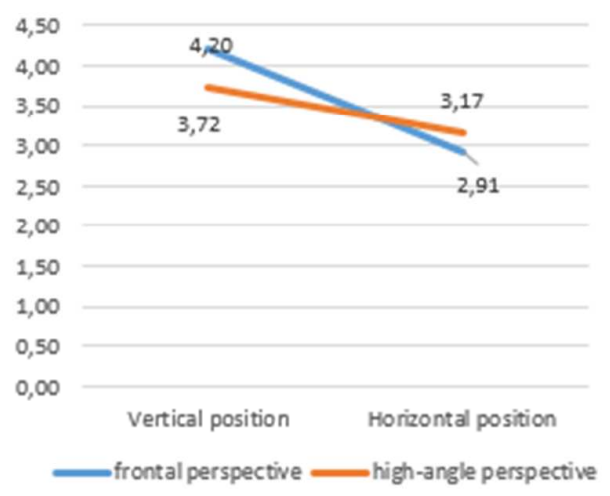

Figure 4: Effect of tilt angle tablet position (study 2)

Study 2: Indirect effect of perspective consistency on purchase intention

\begin{tabular}{llccc}
\hline Antecedent & Mediator & Effect & 95\% LLCI & 95\% ULCI \\
\hline Consistency & Mental & -0.250 & -0.544 & -0.035 \\
of & simulation & & & \\
perspective & & & & \\
\end{tabular}

Table 6: Mediation of mental simulation on purchase intention (study 2) 


\section{Appendix 2: Images used for study 2}

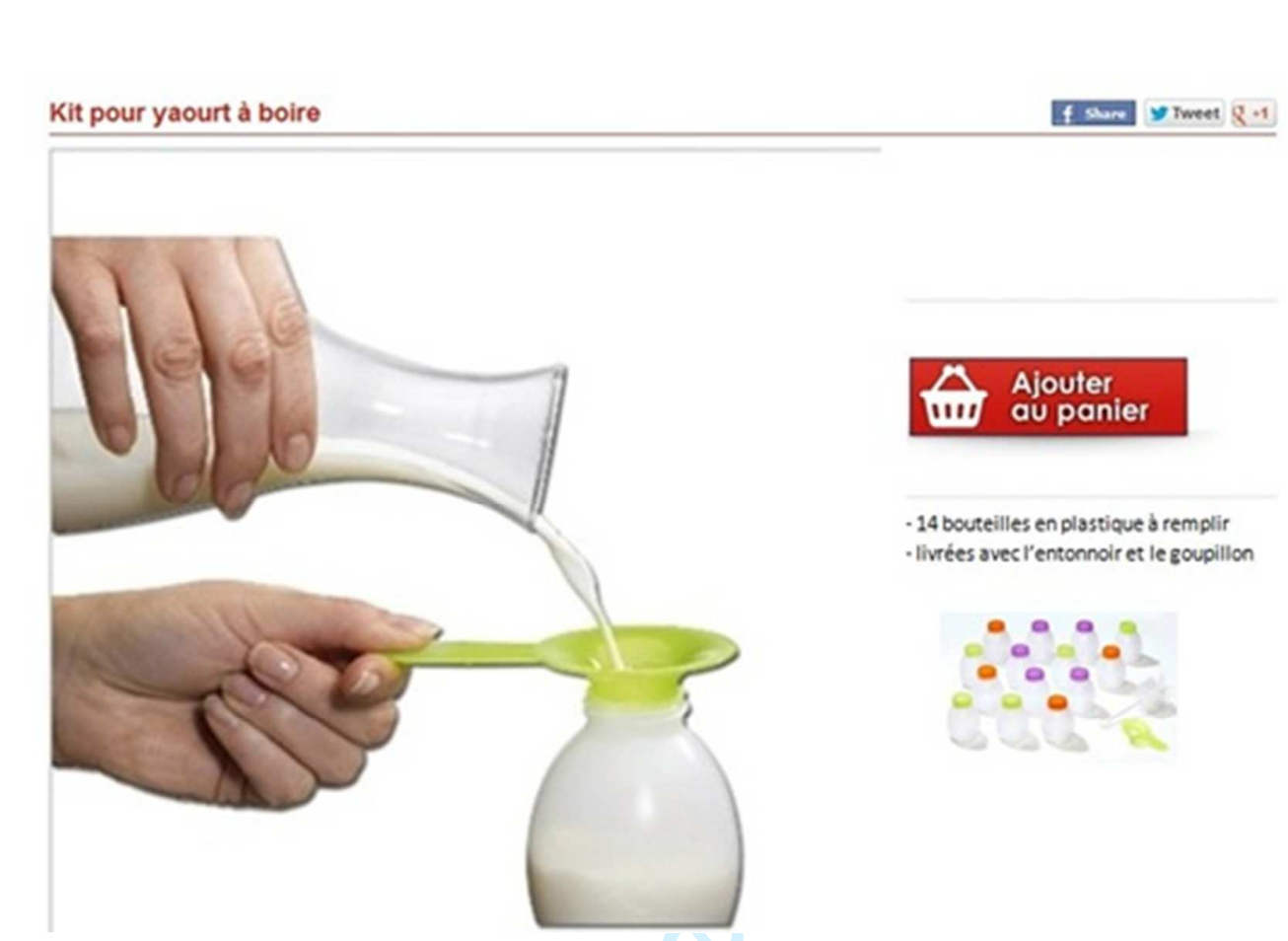

\section{Appendix 1: Image used for study 1}

\section{APPENDIX}

Frontal perspective

High-angle perspective

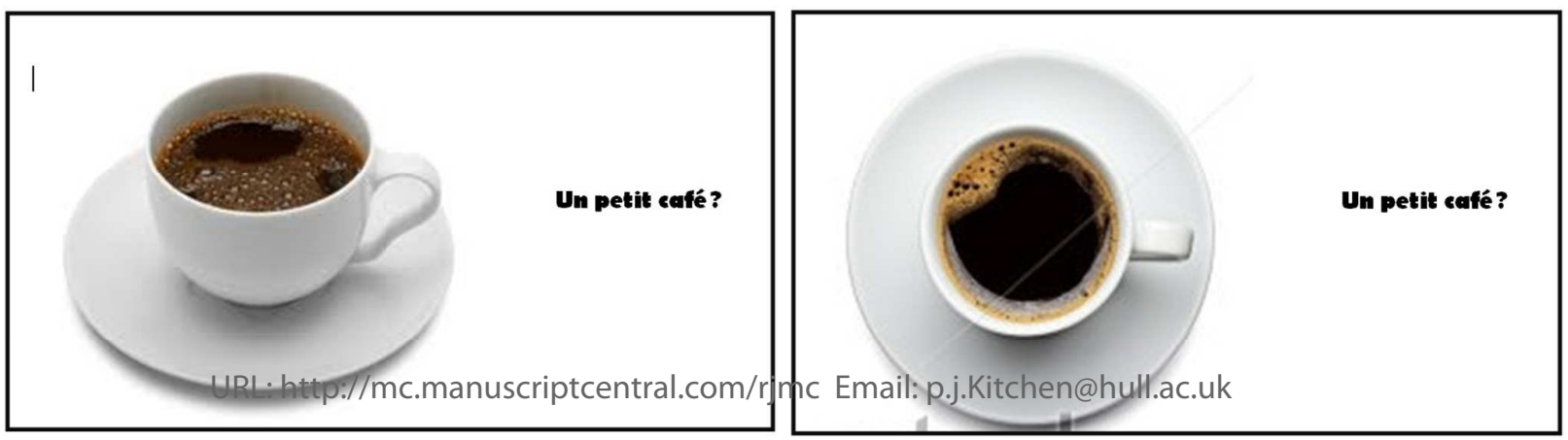


1

2

3

4

5

6

7

8

9

10

11

12

13

14

15

16

17

18

19

20
ANSWERS TO REVIEWERS

Mobile advertising: the effect of tablet tilt angle on user's purchase intentions Journal of Marketing Communications

June 2018

Dear reviewers,

We thank you for your interesting comments and various suggestions that helped us to improve the quality of the manuscript.

In this last version of the manuscript, we added some precisions to the presentation of the results and we edited and proof-read the manuscript so as to be sure there were no mistakes left.

We also carefully examined each of you remark. We addressed each of them in the table below. 
The reviews are in general favourable and suggest that, subject to minor revisions, your paper could be suitable for publication. Please consider these suggestions, and I look forward to receiving your revision.
We thank you for your encouraging remark. We addressed each comment and suggestion of the reviewers.

\section{Reviewer: 1}

Comments to the Author

I believe the manuscript has progressed quite well in addressing the comments provided by the review panel. My major concerns raised earlier are about the conceptual development and theoretical contribution of the manuscript. In this round, the authors have addressed my concerns on these issues. To further improve the manuscript, I hope the authors find the following comments helpful:

1. The statistics in $\S 1$ (on p. 1) might be updated.

2. The reporting of the results of data analysis should be more professional. For example:

(a) Please clarify the measurement scales of the confounding checks in Study 2: "We verified that, in all four conditions, the image was easy to understand and that information in the advertisement was easy to process $(1.4<\mathrm{M}<1.6$; ps $>0.495)$ ". Are the items for the confounding check measured on a 7-pint Likert scale? If so, you might want to report "the image was easy to understand and that information in the advertisement was easy to process (Ms $=1 . ? ? / 7$ vs/ 1.??/7, p > 0.1)" (p. 19).
We thank you for your positive feedback. In this last revised version, we carefully took into consideration each of your suggestions so as to continue improving the manuscript.

We updated the statistics presented in the introduction : "E-commerce growth is primarily being driven by consumers using their mobile devices, phones and tablets, to acquire goods and services (statista, 2018). Retail e-commerce sales reached $\$ 2.3$ trillion in 2017, a 23.2\% increase over the previous year. The mobile share of this stood at $58.9 \%$, or $\$ 1.4$ trillion. In 2021 , mobile e-commerce could rake in some $\$ 3.5$ trillion and then make up almost three quarters $(72.9 \%)$ of e-commerce sales (statista, 2018). Laptop and PC e-commerce drops off, although ecommerce on smartphones and tablets increases dramatically.

We clarified the results presentation by indicating what type of scales had been used to measure the images.

Then we added :

"we used two 7 points Likert scale items and calculated an average score of the two items: "understanding this image requires effort of thought" and "to understand this image, you have to concentrate"

We checked that both images were easy to understand in the two tablet positions. Therefore the analysis gave and compare 4 scores. To be simpler, we chose to indicate only the two extreme scores in the manuscript. Please find the four different scores, showing no significant differences between the four conditions:

Mverticalfrontview $=1.4333$

Mverticalbird'seyeview $=1.4091$

Mhorizontal bird'seyeview $=1.5938$

Mverticalfrontview $=1.6250$

(b) When checking the demographic information of the subjects, it's better to report there is no difference in terms of familiarity of digital tablets and general attitudes towards the experimental
Following your suggestion, we explicitly added in the sentence :

"There was no difference in terms of familiarity with digital tablets and general attitudes towards 


\begin{tabular}{|c|c|}
\hline stimuli (i.e., coffee). & the experimental stimuli". \\
\hline $\begin{array}{l}\text { (c) Results of Study 2: It would be clearer to } \\
\text { report the two ANOVA tests one by one. First, } \\
\text { purchase intention was submitted to two-way } \\
\text { ANOVA. Does the analysis reveal any main } \\
\text { effect of device position and/or ad perspective } \\
\text { (in addition to the interaction effect)? If so, } \\
\text { please report them accordingly, before } \\
\text { proceeding with the contrast analysis. Second, } \\
\text { mental simulation was submitted to two-way } \\
\text { ANOVA. Similarly, reports any main effects, } \\
\text { interaction effect, and the results of contrast } \\
\text { analysis. }\end{array}$ & $\begin{array}{l}\text { Following your suggestion, we indicated the } \\
\text { results of the main effect analysis before } \\
\text { reporting the result of the interaction effect } \\
\text { analysis. Indeed, we indicated that there were } \\
\text { no direct of device position and image } \\
\text { perspective on purchase intention and on mental } \\
\text { simulation ( } p>0.05 \text { ) }\end{array}$ \\
\hline $\begin{array}{l}\text { 3. Please edit and proof-read the manuscript } \\
\text { again to correct the grammar mistakes. For } \\
\text { example, "In doing so ... by underlining the role } \\
\text { of the device tilt angle mental simulation and } \\
\text { purchase intention" (p. 2) might be changed to } \\
\text { "... the role of the device tilt angle, mental } \\
\text { simulation, and purchase intention" or "... the } \\
\text { role of the device tilt angle and mental } \\
\text { simulation in stimulating consumers' purchase } \\
\text { intention". }\end{array}$ & $\begin{array}{l}\text { We thank you for your suggestion. } \\
\text { We edited and proof-read the entire manuscript } \\
\text { again. }\end{array}$ \\
\hline
\end{tabular}

Reviewer: 2

Comments to the Author

Please do a proof reading and make sure there is no mistake in data analysis before final submission.
We thank you for your suggestion. We edited and proof-read the entire manuscript again. We also carefully checked that there were not any mistake in the data analysis before final submission. 